\title{
Reduction of Workforce due to Impact of Covid-19 and Occupational Health and Safety Management at the Workplace
}

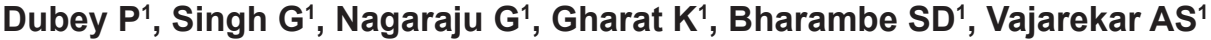

${ }^{1}$ Industrial Hygiene and Safety Section, Health Safety \& Environment Group, Bhabha Atomic Research Centre, Mumbai-400 085, India

\section{ABSTRACT}

COVID-19 pandemic has led to a health crisis as well as a slowdown of industrial activities throughout the world that has resulted in global economic loss. Safety measure of social distancing at workplaces to prevent the spread of coronavirus leads to huge losses especially in the service sector jobs that depend on customerprovider interactions or involve the congregation of a large number of people. Also, the process of equipment and machinery may not function smoothly due to continuous shut down during the lockdown period. As workplaces have been forced to cut down their expenditure and recheck their workforce to maintain social distancing, workers in industries are at a higher risk of losing their jobs.

Fewer workforces at the workplace have increased workload on available workers along with insecurity due to pandemic. Under these circumstances, the responsibility of the management is to keep a balance between production, profit and safety at the workplace as well as to keep employees motivated and to cope with the stressful environment. This paper addresses the challenges and the methods to prevent and mitigate occurring of accidents at workplaces which are having reduced workforce and malfunctioning of equipment \& machinery as compared to pre-COVID 19 scenarios.

Key word: Accident, Covid-19, Stress, Safety, Work environment

\section{Introduction}

$\mathrm{n}$ the present condition of the pandemic, the industries world over, especially manufacturing organizations are striving to increase the productivity and maintain the quality of products with reduced and mentally \& physically stressed workforce due to prevailing pandemic. Many production industries are facing new challenges to (i) Stay competitive (ii) Maintain sufficient

DOI: https://doi.org/10.3126/ijosh.v10i2.33287

Date of submission: 04.11.2020

Date of acceptance: 10.12 .2020

\section{Corresponding Author}

Praveen Dubey

Scientific Officer (D)

Industrial Hygiene and Safety Section

Bhabha Atomic Research Centre, Mumbai- 85

India

Email: praveend@barc.gov.in

Tel: +91 (022) 25592236

Orcid ID: 0000-0002-9264-4377 and motivated workforce at the workplace and (iii) Avoid accidents and provide safe and occupationally healthy \& hygienic environment with the reduction of workforce. The third one is the greatest challenge in present scenario. ${ }^{1,2}$

The overall impact of COVID-19 pandemic on India's economy during the period between April to June 2020 , as compared to the same period in the previous year is estimated GVA (Gross Value Added) loss of about three trillion rupees. Finance sector, real estate sector and professional services were estimated to be hardest hit by COVID-19. ${ }^{3}$

In our research institute too, many activities have been affected due to COVID-19 e.g. in construction, manufacturing components and other R\&D activities. The rate of infection due to Coronavirus in India is low when compared to other countries. ${ }^{4}$ The precautionary

\section{(c) (i) (8)}

This journal is licensed under a Creative Commons AttributionNon Commercial 4.0 International License. 
measures adapted to control and mitigation of COVID19 pandemic will be an important consideration for the country's major industries.

\section{Immediate Issues}

Unlike at our homes, workplaces have a presence of various workers commuting from far \& near places in huge numbers using various means of transport. A new challenge being faced is to build confidence among employees that they are returning to work in a safe and healthy, hygienic environment. Also, to ensure them that equipment/machinery on which they are likely to work have been maintained to work even after a long period of shut down due to long lockdown. Before pandemic due to the layout of workplaces, the workforce might be working together in close proximity to each other. However, as a precautionary measure of maintaining social distance, employees may find it difficult to change from group activity to work little independently by maintaining the distance from each other.
Because of these aspects, there is always a certain kind of risk associated with reopening of workplaces post Covid-19, requiring attention to maintain safety with responsibility. Negligence even by ignorance might have a great potential threat to cause the spread of the virus among employees.

COVID-19 crisis is likely to impact workers differently because of issues like the threat of viral infection, health vulnerability, organizational changed perceptions, downward change in income levels and seniority/job tenure. Curtailment in the workforce at the job site to maintain social distancing, utilization of only available skilled manpower would be the contributing factors for the derailment of occupational safety at workplaces. Besides this, a new factor of stress and anxiety among the workforce due to COVID-19 can induce behavioral change among them, leading to enhanced risk impairment at the workplace. The absenteeism of workforce/termination of a substantial number of workers may cause high-level stress in continuing activities for maintaining the desired output levels.

Table 1: Estimated Gross Value Added (GVA) loss during April-June 2020 as compared to April-June 2019. ${ }^{3}$

\begin{tabular}{lc}
\hline Nature of Industry & GVA Loss \\
\hline Financial, real estate \& professional services & $17 \%$ \\
Mining \& quarrying & $14.3 \%$ \\
Electricity gas, water supply and other utility services & $13.9 \%$ \\
Construction & $13.3 \%$ \\
\hline Trade, Hotel, Transport, communication etc. & $9.7 \%$ \\
Manufacturing & $6.3 \%$ \\
\hline Agriculture, forestry \& fishing & $1.3 \%$ \\
\hline Public administration, defense and other services & $0.4 \%$ \\
\hline
\end{tabular}

Table 2: Possible effects of the COVID-19 pandemic

\begin{tabular}{|c|c|}
\hline Phase/ Pandemic Wave & Possible Effects which need to be addressed \\
\hline $1^{\text {st }}$ & $\begin{array}{ll}\text { - } & \text { Immediate mortality and morbidity } \\
\text { - } & \text { Stress and panic situation } \\
\text { - } & \text { Lack of information } \\
\text { - } & \text { Health and Hygiene conditions }\end{array}$ \\
\hline $2^{\text {nd }}$ & $\begin{array}{ll}\text { - } & \text { Impact of resources restriction } \\
\text { - } & \text { Non availability of resources } \\
\text { - } & \text { Reduction in work efficiency } \\
\text { - } & \text { Degrading in quality and quantity of material }\end{array}$ \\
\hline $3^{\text {rd }}$ & $\begin{array}{l}\text { - } \quad \text { Chronic Effects due to } 1^{\text {st }} \text { and } 2^{\text {nd }} \text { wave prevailing conditions } \\
\text { - } \quad \text { Build-up of physical and psychological stress }\end{array}$ \\
\hline $4^{\text {th }}$ & $\begin{array}{l}\text { - } \quad \text { Acute Psychic trauma } \\
\text { - } \quad \text { Effect of mental well being } \\
\text { - } \quad \text { Stress due to economic losses, etc. }\end{array}$ \\
\hline
\end{tabular}


Additionally, the uncertainty of worker's availability might affect the output level and also may result in situations that will endanger their health and safety.

With a changing work environment with a hanging sword of pandemic condition, there is a need for revision of work areas, work procedures. Management of available resource utilization to identify and assess associated risks in both physical and psychosocial working environments is the starting point for managing Occupational Safety and Health (OSH) under COVID19 measures. Expected various Phases/Pandemic waves and corresponding possible effects which need to be addressed are shown in Table-2.

COVID-19 would have repercussions on mental health and psychological effects on the workforce. Degrading trending economic conditions due to fallout of COVID19 are expected to continue for the next several years. ${ }^{5}$

Managements have to oblige to revise their risk assessment plan and to consider all risks, including those affecting mental health whenever there is a change in the work process.

While doing the risk assessment, attention would be required to minimize anomalies or situations that have the potential to cause problems and to find their solutions to help the organization become more resilient in the long term.

\section{New physical spaces}

COVID-19 primarily spreads through respiratory droplets or probable contact with contaminated surfaces. Possibility of infection to the virus at the workplace may increase due to travelling to and from work, from the area with potential for local community transmission. World Health Organization (WHO) recommends at least 1 metre physical distance from others which converts to providing at least 10 square metres space, for every worker to prevent the spread of transmission, otherwise virus can spread in a crowded workplace. ${ }^{1}$ Centre for Disease Control and Prevention (CDC) recommends maintaining social or physical distancing, of at least 6 feet (about 2 metres) from each other either at workplaces or at public places ${ }^{6}$.

The risk of exposure to COVID-19 depends on the likelihood of coming within 2 metres of infected person without face mask and having frequent physical contact with people who might have been already infected with COVID-19 or by contact with contaminated surfaces and objects with the virus. ${ }^{1}$ Maintaining a physical distance of at least 2 metres between the persons at all workplace would have less probability of spread of COVID-19. In a collaborative office space, this can be achieved by the reduction in the total number of seats (Figure 1). In a place occupied by multiple people, there is the need to change workplace layout, rearranging and staggering of occupants for working, change in the office timings, to prevent the spread of disease. In a typical workplace, the existing layout and the rearranged workplace is shown in Figure $1 .{ }^{7}$

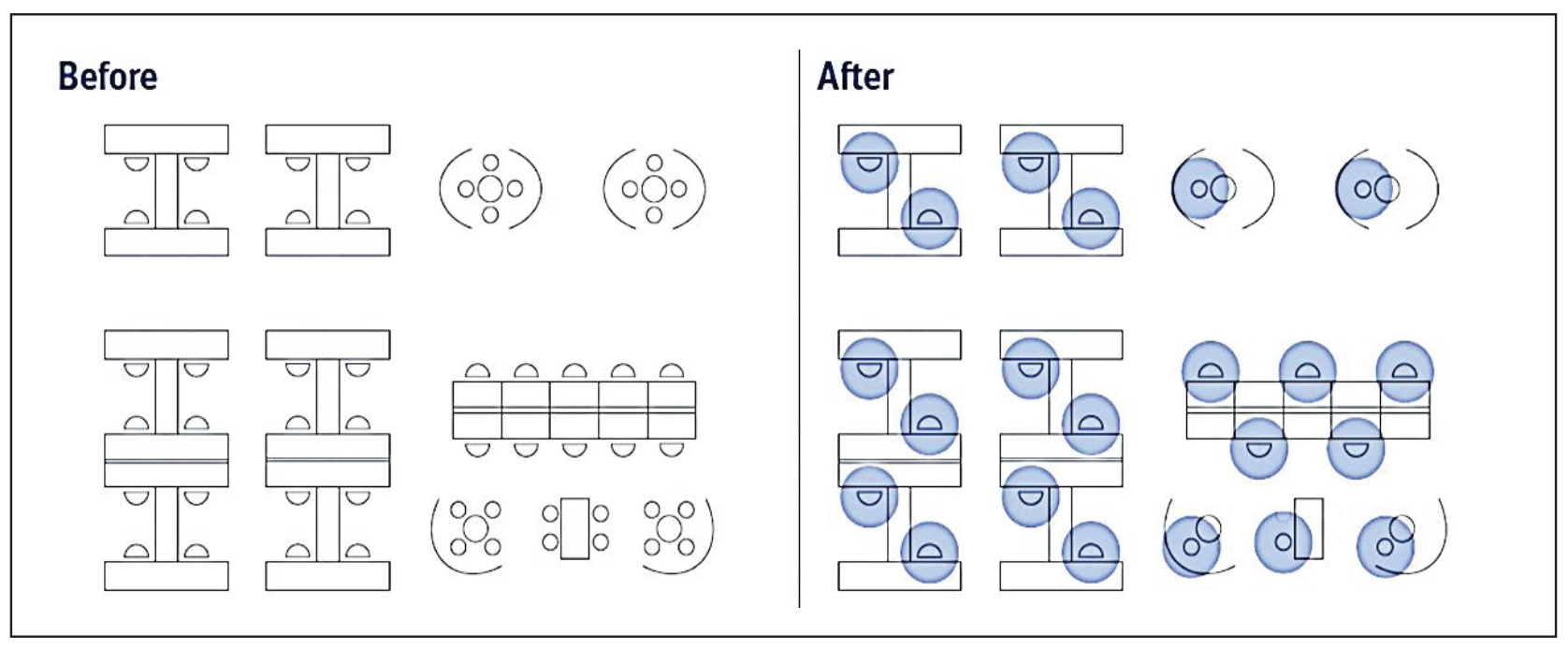

Figure 1: A graphical example of alteration of collaborative office to promote individual workstations. 


\section{New methods for communication}

Good communication plays an important role in achieving productivity and maintaining strong working relationships at all levels of an organization. In this pandemic situation, it is an essential task to communicate appropriate information to workforce so as to build the confidence among them. It is more important to pass on the real-time information to the entire workforce with effective, suitable and contactfree methods. In a nutshell for communication aspects, management is responsible for

- Informing all employees of revised policies and procedures

- Connecting all employees while maintaining social distancing

- Reinforcement of best practices in infectioncontrol at workplaces

- Initiating information enhancement and program for psychological well being

- Ensuring the safety and health of the workforce

- Reassure students, visitors and contractual workforce

- Initiating actions on notification of any case of COVID-19 particularly for isolation of that employee, sanitization/ disinfection of the respective workplaces etc.

There is a need to communicate workforce with in situ and contactless information. Digital resources for communication and digital signage (electronic message boards) and poster messages are the best tools for wide circulation of information.

\section{New way to Promote: "Respect for Human being"}

The management needs to work collaboratively with employees to create a positive work environment. That means developing positive relationships with employees and two-way feedback loops to address any problems as and when they face them. This allows the management to understand patterns of behavior, if any, among workers, and build procedures that reflect these workflows. In the Covid-19 era, it is necessary to strengthen the bonding between employer and employees.

This may be done through:

- Physical and Psychological Fatigue Awareness Programme i.e., how to come out from stress developed due to work constraints with reduced staff strength.

- Flexible Time, i.e., changing shifts, workdays

- Prioritization- What can wait? What needs to be done on priority?

- Burnout- Signs, Symptoms, Safe to speak up i.e., in case of stress, how to and with whom should be discussed at the workplace.

- Proper in-situ Communication

- Initiation to recognise fatigue

\section{Role of Safety Professionals}

Safety Professionals would require to play a major and important role in ensuring an effective and safe workplace for workers. It is important to draw up revised crisis contingency plans for the shutdown of the facilities and re-start of the same after the end of the lockdown period. The challenges are at large as uncertainty is expected at every stage starting from abrupt/ sudden shutdown and re-starting of the facility which involves gradual easing of restrictions and phase-wise opening.

Safety professionals need to keep abreast of the latest information \& guidelines, the different types of incidents happening globally, besides, to ensure the healthy workplace and also monitoring of the health of the employees.

Before initiation of work at workplace or any new activity, as a safety professional, inputs must be provided to workers and/or their representatives regarding the health and safety-related information and new challenges in the activity. Engaging with workers in assessing risks and developing responses is an important part of good health and safety practice. This will help in deciding upon the apt preventive measures and to ensure that they are implemented successfully. It should be ensured that project trainees, contract/ casual staff have access to the same information as direct employees.

Jobs that require a group of personnel working together are likely to have physical contact with coworkers and have great potential of causing the spread of COVID-19. Management with the support of safety advisor needs to carry out rapid risk assessments for the determination of potential exposure risk to enhance the existing preventive measures. This activity may get repeated depending on the nature of work having specific requirements. 


\section{Rethinking Workplace}

A restart of the workplace post-COVID-19 need systematic planning with respect to manpower management, utilization of the materials and equipment at the fullest extent apart from managing with the available manpower, health checks and monitoring of employees, maintenance of the workplace with sanitized status etc.

Reopening of workplaces will still need to observe regulations governing social distancing, employee gatherings and hygiene practices. Ensure proper ventilation of the workplaces. This needs a proactive approach in rethinking physical workplaces.

\section{Initiatives towards Prevention and Mitigation}

\section{Covid-19 Safety Guidelines}

For the benefit of employees and also to ensure the safe come back of employees after lockdown, comprehensive Guidelines for "COVID-19 Mitigation Measures" have been prepared and given wide publicity [10]. These guidelines ensure that all required precautions are taken by the employees including continuously wearing of face masks and maintaining the social distancing norms by every individual to maintain the hygiene of workplaces at frequent intervals.
The key objectives of these guidelines are:

i) Prevent entry of potential Covid-19 affected persons

ii) Minimise the possibility of cross-contamination

iii) Ensure a healthy work environment by proper hygiene at workplaces

iv) Ensure proper operation/function of the instruments/ equipment post lockdown

v) Support quick contact tracing if anybody is detected with COVID-19

vi Establish confidence-building measures for the employee

In addition to this, monitoring the health status of employees and rearrangement of the seating plans to ensure social distancing etc are in place to move ahead for normalization of activities, to ensure equipment/ machinery are brought into good working conditions.

\section{Reduced Workforce and Remote work policy:}

The implementation of safe work practices to limit exposure to COVID-19 at work requires first assessing the risks, and then implementing the hierarchy of controls. This means putting in place control measures first to eliminate the risk and if this is not possible, minimise worker exposure. In case of physical presence required for workplace, all safety measures along with the precautions revised due to Covid19 shall be followed such as Personal Protective Equipment (PPE). ${ }^{9}$

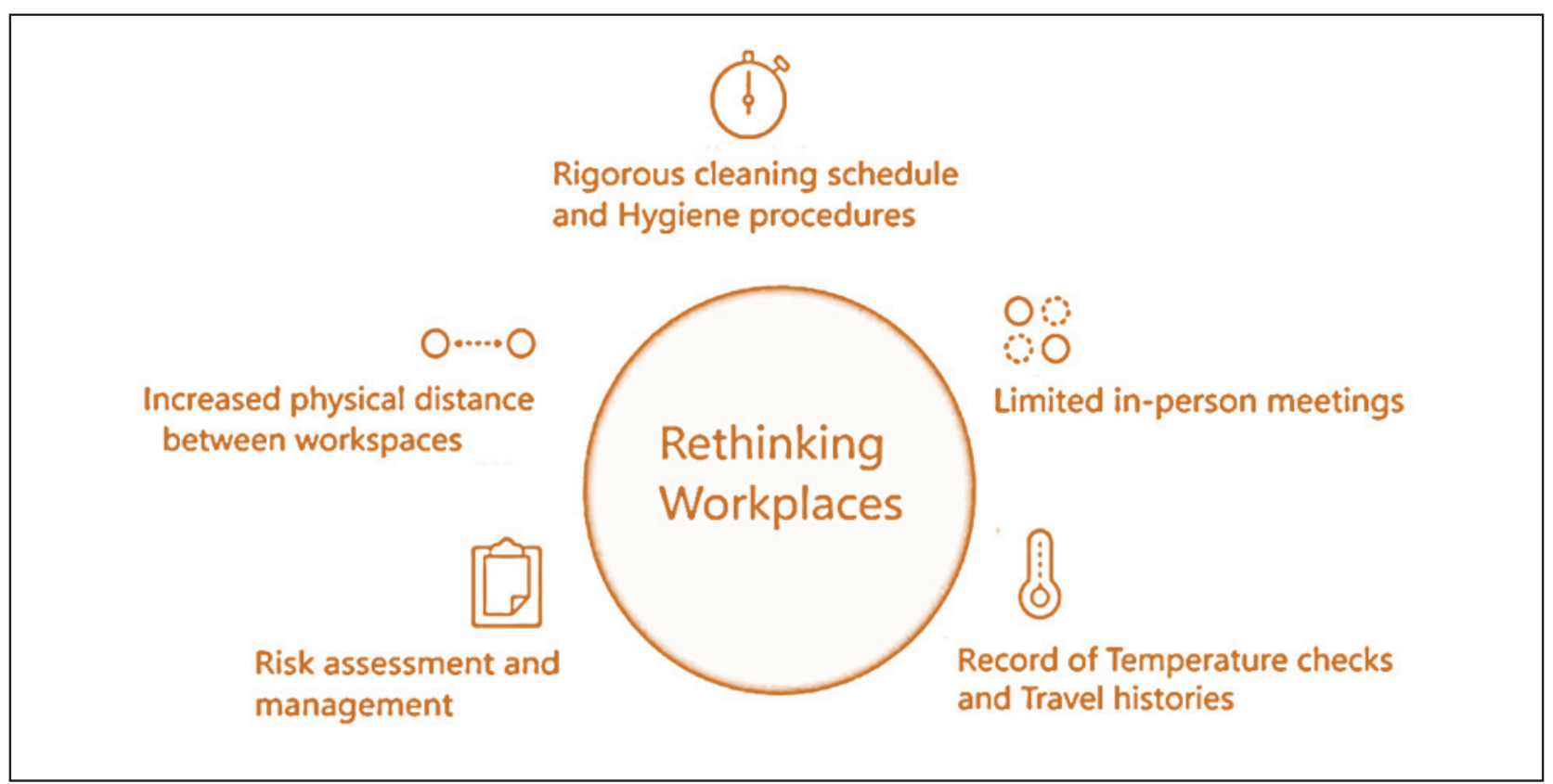

Figure 2: Rethinking process cycle for workplace (Source: Forrester [8]) 
The following methods shall be adopted:

1. Only essential work shall be carried out for the time being on priority basis

2. As far as possible, physical contact between workers (e.g. during meetings or during breaks) shall be reduced

3. Physical interaction shall be eliminated if possible, else limited by distancing/ closed or covered barriers with fire retardant material.

4. Posters that encourage staying home when sick, cough and sneeze etiquette and hand hygiene shall be placed at the entrance and in other conspicuous locations

As future situations might not permit working together in the office, emphasis needs to be given to automation based/remote work. With these requirements, initiatives shall be required to be taken to develop infrastructure for automation-based work that creates more flexibility.

Sanitisation Policy: High contact surfaces such as staircases including railings, door knobs/handles elevator buttons, handrails / door handles and call buttons, escalator handrails, public counters, intercom systems, equipment like telephone, printers/scanners, and other office machines should be cleaned twice daily by mopping with a linen/absorbable cloth soaked in $1 \%$ sodium hypochlorite or any other disinfectant liquid. ${ }^{9}$ Supply of soap and water or appropriate hand sanitizer at convenient places shall be ensured and posters shall be displayed advising workers to wash their hands frequently.

\section{Monitoring and Tracking System for employees:}

Despite applying all feasible safety measures, chances are there that an employee may be identified for risk of COVID-19 infection. Confirmation of Covid-19 infection, prevention of infection and control on the spread of virus shall be ensured by keeping respective stakeholders in a closed loop. Policies shall be initiated for flexibility of remote working to limit presence at the workplace, when needed.

\section{Medical Facilities:}

On showing any sign of respiratory illness or sore throat, the worker shall get tested. Any new case needs to be identified quickly and controlled swiftly. On detection of a COVID-19 case, medical follow up is to be ensured as per Government Directives. Contact Tracing is to be initiated. Appropriate Authority shall take the initiative for contact tracing as per Guidelines for “COVID-19 Mitigation Measures”. Home Quarantine is to be followed as per Government Directive. This will require abundant hospital and administrative resources which involves financial and logistic planning. ${ }^{10}$

\section{Dissemination of Information}

Industrial Hygiene and Safety Section (IHSS) took the initiative to empower the employees with the right information and to take precautions as per the advisories being issued by the Ministry of Health \& Family Welfare. ${ }^{10}$ To prevent the spread of coronavirus inside the premises of research centre, IHSS has designed awareness posters on COVID-19 in English, Hindi and Marathi languages which contain simple messages on wearing masks, social distancing, washing hand etc. These posters have been widely circulated in digital form and are also displayed at prominent location through Digital Scrolling Poster Displays (DSPD) systems on COVID-19.

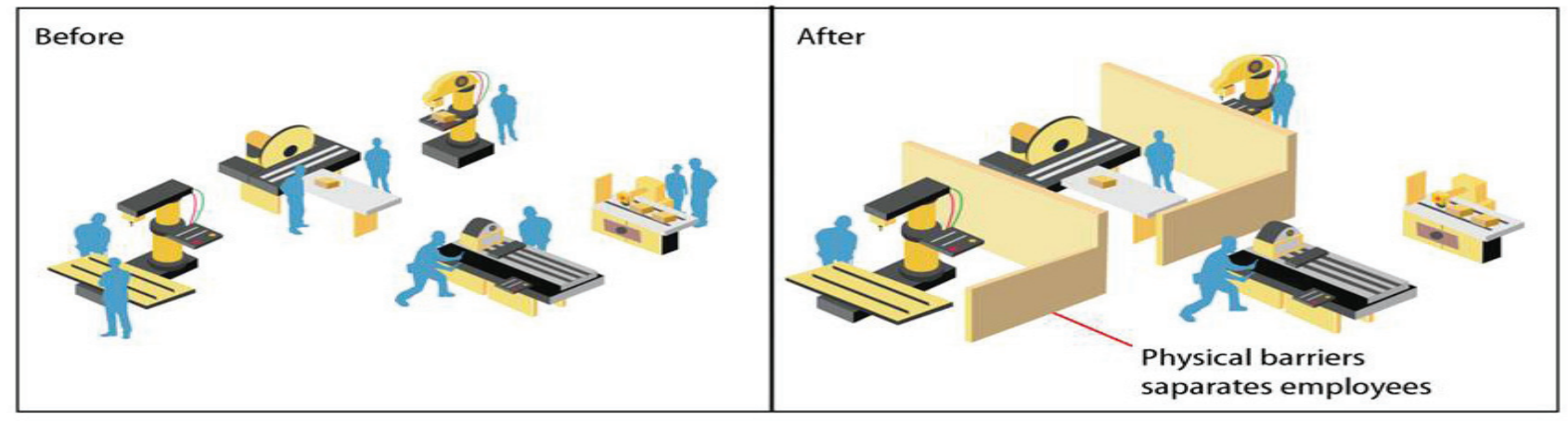

Figure 3: Ensuring physical distancing at shop-floor 

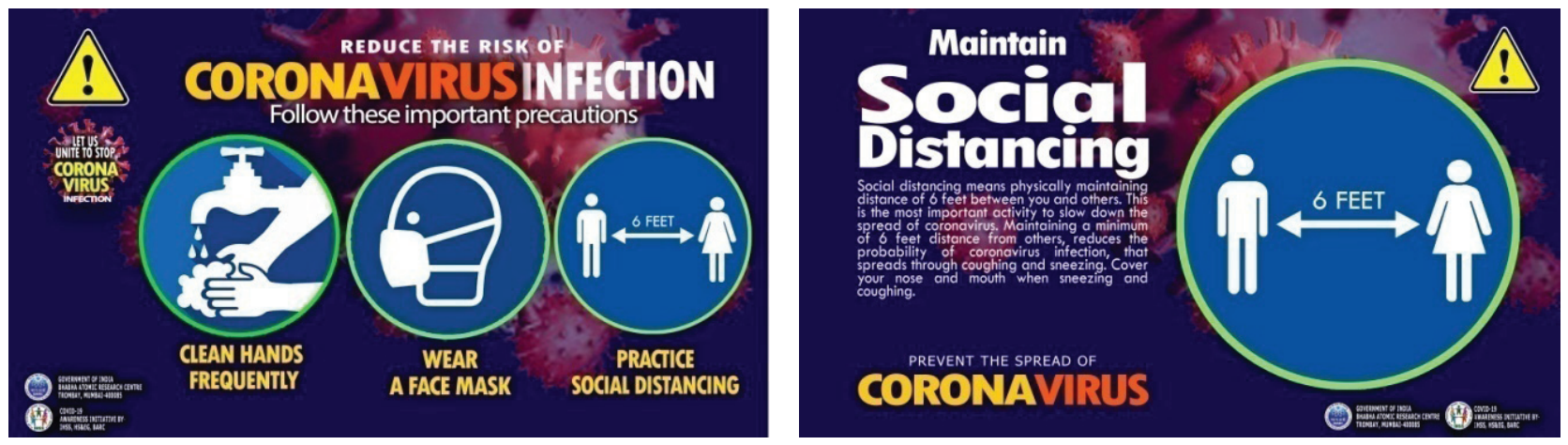

Figure 4: COVID awareness programme

\section{Conclusion}

COVID-19 has significantly affected the economy and has caused reduction in the workforce due to migration [11]. Various measures adopted at the workplace to prevent transmission of COVID-19 among workers include frequent hand-washing or disinfection with alcohol-based hand sanitizer, respiratory hygiene such as covering coughs, the physical distancing of at least 2 metres or more according to the national recommendations, wearing of masks where distancing is not possible, regular environmental cleaning and disinfection and limiting unnecessary travel.

It is essential to impart training \& education to staff and managers to increase awareness of COVID-19. Rapid

\section{References}

1. World Health Organization. Considerations for public health and social measures in the workplace in the context of COVID-19. WHO guidelines 2020. Geneva, Switzerland: World Health Organization. 2020 May 10. Available at: https://www.who.int/.

2. Shaw WS, Main CJ, Findley PA, Collie A. Opening the Workplace After COVID-19: What Lessons Can be Learned from Return-to-Work Research. Journal of Occupational Rehabilitation. 2020;30: 299-302. Available at: https://link.springer.com/article/10.1007/ s10926-020-09908-9.

3. Sandhya K. Estimated economic impact from COVID-19 on India's GVA April-June 2020 by sector. 2020. Available from: https://www.statista.com/ statistics/1107798/.

4. World Health Organization. WHO COVID-19 Weekly Operational Update- 9-16 October 2020. Geneva: World Health Organization. 2020. Available from: https:// www. who.int/publications/m/item/weeklyupdate-on-covid-19---16-october-2020 sharing of information is vital for decision-makers to take actions related to occupational health. Policies and messages need to be quickly disseminated to the workforce. The management of people with COVID-19 or their contacts is also critical e.g. requiring workers who are unwell or who have developed symptoms to stay at home, self-isolate and contact a medical professional or the local COVID-19 information helpline for advice on testing and referral.

Acknowledgement: The authors sincerely acknowledge their deep sense of gratitude to Mr. Suresh Babu R.M., Director, Health, Safety \& Environment Group, BARC for his constant encouragement and support throughout this study.

5. Kohli P, Virani SS. Surfing the Waves of the COVID-19 Pandemic as A Cardiovascular Clinician. Circulation. 2020 Jul 14;142:98-100. Available from: https:// www . ahajournals.org/doi/10.1161/ CIRCULATIONAHA.120.047901.

6. "Social Distancing- Keep a Safe Distance to Slow the Spread". Centre for Disease Control. Atlanta. 2019. Available from: https://www.cdc.gov/ coronavirus/2019-ncov/prevent-getting-sick/socialdistancing.html.

7. Miller H. Embracing a New Reality: Workplace Strategy Insights for COVID-19 and Beyond. COVID-19 Research Report. 2020 Jun 02. Available from: https://www.hermanmiller.com/content/dam/ hermanmiller/documents/covid_19/embracing_a_ new_reality.pdf.

8. Balaouras S. Entering the new normal: How to safely bring your workforce back. Forrester. 2020 Apr 20. Available from: https://go.forrester.com/blogs/ entering-the-new-normal-how-to-safely-bring-yourworkforce-back/. 
9. COVID- 19: Guidelines on disinfection of common public places including offices 2020. Ministry of health and Family Welfare. Government of India. Delhi. Available from: https://www.mohfw.gov.in/pdf/ Guidelines on disinfection of common public places including offices.pdf.

10. SOP on preventive measures to contain spread of COVID-19 in Offices and work places. Ministry of
Health \& Family welfare. Government of India. 2020 Jun 04. Available from: https://www.mohfw.gov.in/ pdf/1SoPstobefollowedinOffices.pdf

11. Khanna A. Impact of Migration of Labour Force due to Global COVID-19 Pandemic with Reference to India. Journal of Health Management. 2020 Jun;22(2):18191. Available from: https://journals.sagepub.com/doi/ full/10.1177/0972063420935542. 